\title{
Nociception-specific blink reflex: pharmacology in healthy volunteers
}

\author{
JCA Marin ${ }^{1}$, AR Gantenbein ${ }^{1,4,5}$, K. Paemeleire ${ }^{1,6}$, H. Kaube ${ }^{1,7}$ and PJ Goadsby ${ }^{1,2,3^{*}}$
}

\begin{abstract}
Background: The physiology and pharmacology of activation or perception of activation of pain-coding trigeminovascular afferents in humans is fundamental to understanding the biology of headache and developing new treatments.

Methods: The blink reflex was elicited using a concentric electrode and recorded in four separate sessions, at baseline and two minutes after administration of ramped doses of diazepam (final dose $0.07 \mathrm{mg} / \mathrm{kg}$ ), fentanyl (final dose $1.11 \mu \mathrm{g} / \mathrm{kg}$ ), ketamine (final dose $0.084 \mathrm{mg} / \mathrm{kg}$ ) and $0.9 \%$ saline solution. The AUC (area under the curve, $\mu \mathrm{V}^{*} \mathrm{~ms}$ ) and the latency (ms) of the ipsi- and contralateral R2 component of the blink reflex were calculated by PC-based offline analysis. Immediately after each block of blink reflex recordings certain psychometric parameters were assessed.

Results: There was an effect due to DRUG on the ipsilateral $\left(F_{3,60}=7.3, P<0.001\right)$ AUC as well as on the contralateral $\left(F_{3,60}=6.02, P<0.001\right)$ AUC across the study.

A significant decrement in comparison to placebo was observed only for diazepam, affecting the ipsilateral AUC. The scores of alertness, calmness, contentedness, reaction time and precision were not affected by the DRUG across the sessions.

Conclusion: Previous studies suggest central, rather than peripheral changes in nociceptive trigeminal transmission in migraine. This study demonstrates a robust effect of benzodiazepine receptor modulation of the nociception specific blink reflex (nBR) without any $\mu$-opiate or glutamate NMDA receptor component. The nociception specific blink reflex offers a reproducible, quantifiable method of assessment of trigeminal nociceptive system in humans that can be used to dissect pharmacology relevant to primary headache disorders.
\end{abstract}

Keywords: Migraine; Trigeminovascular system; Nociception specific blink reflex (nBR); Pharmacology

\section{Background}

The physiology and pharmacology of head pain underpins understanding of the various syndromes and development of new therapies for conditions such as migraine and cluster headache. Migraine is an episodic brain disorder that affects about $15-18 \%$ of the population [1], is the most common cause of disability due to a neurological disorder [2] and has been estimated to be the most costly neurological disorder in the European Community at more than $€ 27$ billion per year [3]. Major therapeutic development, in the form of relatively specific and effective acute $[4,5]$

\footnotetext{
* Correspondence: peter.goadsby@kcl.ac.uk

'NIHR-Wellcome Trust King's Clinical Research Facility, King's College Hospital, London, UK

${ }^{2}$ Department of Basic and Clinical Neuroscience, Institute of Psychiatry,

Psychology and Neuroscience, King's College, London, UK

Full list of author information is available at the end of the article
}

and preventive $[6,7]$ treatments of migraine have provided impetus to understand their mechanism of action. Since activation, or the perception of activation, of pain-coding trigeminovascular afferents underlies most disabling primary headaches [8], understanding human trigeminal mechanisms is essential for therapeutic development. The description of a method for activating the trigeminal system in humans to study pain-induced responses [9] has spurred many studies of this crucial pathway [10].

The blink reflex (BR) is a physiological, protective trigeminofacial reflex aimed at facilitating eyelid closure as a response to a threatening and potentially harmful stimulus [11]. In clinical practice the BR can be elicited when the skin innervated by the supraorbital nerve is electrically stimulated and a compound muscle action potential (CMAP) from the surface of the orbicularis

\section{实 Springer}


oculi muscle is recorded. The afferent portion of BR is supplied by branches of the trigeminal nerve, and the efferent volleys are conducted by branches of the facial nerve. Suprasegmental influences on the BR are less well understood, but evidence from studies in patients with movement disorders, stroke and multiple sclerosis suggest input from the central cortex, basal ganglia and thalamus [12]. The reflex response consists of three components $-\mathrm{R} 1, \mathrm{R} 2$, and $\mathrm{R} 3$. R1 is mediated by exteroceptive A-beta fibers that project to low-threshold mechanoreceptive neurons in the pons $[11,13]$. This response has an ipsilateral oligosynaptic reflex arc connecting the Gasserian ganglion to the pontine sensory nucleus of the trigeminal nerve and subsequently to the ipsilateral facial nucleus [14]. The $\mathrm{R} 2$ response is mediated by A-beta and A-delta fibers, projecting to wide dynamic range (WDR) neurons in the medulla including this of the spinal trigeminal nucleus [15]. R3 is mediated by A-beta and A-delta fibers and the precise connections are debated [16]. R3 and R2 are bilateral responses elicited by both noxious and innocuous stimuli. Only R2 can be elicited by selective activation of nociceptors [17]. Kaube and colleagues [9] developed a novel concentric electrode to allow specific study of nociceptive components of the R2 component of the reflex, the nociception-specific blink reflex (nBR).

It has been reported that fentanyl, an opioid receptor agonist, and diazepam both reduce the R2 component of the blink reflex [18]. Ketamine, despite its use in pain [19], has only infrequently been studied in migraine $[9,20]$, and most recently in migraine aura [21]. In this study we sought to explore the pharmacology of the nociceptive portion of the $\mathrm{R} 2$ response using the novel concentric electrode, and thus provide data in humans on some aspects of the pharmacology of this important synapse.

\section{Methods}

\section{Demographics}

The study was approved by The National Hospital for Neurology and Neurosurgery and The Institute of Neurology Joint Research Ethics Committee and Directorate for Research and Development. Male volunteers $(n=31)$ aged between 21 and 37 years underwent initial screening assessment, which included a careful history and physical examination, after signing an informed consent document that explained and described the study. Ten subjects were unsuitable because of intercurrent medical issues $(n=6)$ or for practical $(n=4)$ reasons, the latter being that they could not agree to attend on repeated occasions. Twenty-one non-smoking [22] subjects $27 \pm 4$ years old (mean $\pm \mathrm{SD}$ ) with unremarkable medical history, including no history of a headache disorder, normal physical examination and clinical laboratory tests, including negative urine drug screening, were recruited into the study. None of the volunteers received any prescribed medication for 30 days prior to the screening or after entering the study, for its entire duration. No medication was used during the $24 \mathrm{~h}$ prior to the recordings. Alcohol consumption was restricted to less than 10 units per week, with no intake for $24 \mathrm{~h}$ prior to and after each recording.

\section{Recordings}

All recordings were carried out between 9.00 and 17.30, with at least one common to all investigator blinded to the treatment (JCAM), under similar conditions and using the same verbal instructions on each occasion. The subjects were lying supine, in a comfortable adjustable bed in a warm room with dim light, keeping their eyes closed during the recordings. When required, gentle pressure was applied on the eye lids by an eye pad, helping the subjects to relax, in order to avoid interference by eyelid fluttering and thus reduce noise. EMG recordings were obtained from bilateral gold-plated surface electrodes placed infraorbitally over the belly of the orbicularis oculi muscle (different) and the lateral orbital ridge (indifferent); acquisition band width 1 to $1000 \mathrm{~Hz}$ (in isolated cases the lower cut off frequency was increased from 1 to $20 \mathrm{~Hz}$ to avoid clipping of the signal due to pronounced EOG responses), sampling rate $2.5 \mathrm{kHz}$ (750 data points/sweep), sweep length $300 \mathrm{~ms}$, amplifier gain 10,000 X (micro 1401, Signal Version 2, Cambridge Electronic Design, UK).

\section{Stimulation}

Blink reflexes were elicited with a custom built concentric electrode in using a printed circuit board design: central platinum cathode (D: $0.5 \mathrm{~mm}$ ) and an external anode ring (D: $6 \mathrm{~mm}$; thickness $1 \mathrm{~mm}$ ), providing a stimulation area of $20 \mathrm{~mm}^{2}$, placed about $10 \mathrm{~mm}$ above the right supraorbital foramen [9]. Stimulation was performed with a constant current source (Stimulator DS7A Digitimer, UK) by delivering a train of three square wave monopolar (positive) pulses [23], each lasting $0.5 \mathrm{~ms}$, with an interpulse interval of $4 \mathrm{~ms}$, maximum voltage $400 \mathrm{~V}$. The current intensity for nociception-specific stimulation was $0.5-1.8 \mathrm{~mA}$ (mean $0.95 \pm 0.19 \mathrm{~mA}$ ), representing $2-4$ times individual threshold for pin-prick perception (mean $0.31 \pm$ $0.06 \mathrm{~mA}$ ) [24]. Each session (of a total of four) consisted of four blocks (one at the base line and one after each dose, see below), separated by 10 min. Each block consisted of seven sweeps with an inter-stimulus interval of 12-18 s (randomized, uniform distribution). Grounding to earth was secured by a moist wrist band electrode or by a standard disposable ECG gel electrode placed over the mastoid protuberance. 


\section{Study design}

In a single-center, randomized, double-blinded, placebocontrolled, crossover, four-arm study, the sensitivity of the blink reflex, as a marker of the central activity of diazepam, fentanyl and ketamine, was assessed versus specific CNS related parameters.

The volunteers were randomly assigned to receive a sequence of four treatments each, on four different occasions, separated by a washout period of a minimum four days.

\section{Treatments}

The subjects were cannulated and received either a ramped dose of intravenous diazepam: initial dose $0.03 \mathrm{mg} / \mathrm{kg}$ with two subsequent increments of $0.02 \mathrm{mg} / \mathrm{kg}$ each [25]; intravenous fentanyl: initial dose $0.37 \mu \mathrm{g} / \mathrm{kg}$ with two additional increments of $0.37 \mu \mathrm{g} / \mathrm{kg}$ each [26, 27]; intravenous ketamine: initial dose $0.028 \mathrm{mg} / \mathrm{kg}$ with two subsequent identical increments of $0.028 \mathrm{mg} / \mathrm{kg}$ [28-30], or intravenous placebo. Placebo was given as pure saline infusion and the active drugs were mixed with saline solution, all administrated from a $50 \mathrm{ml}$ volume syringe. Each infusion (dose increment), including placebo increments, was delivered over two minutes $(300 \mathrm{ml} / \mathrm{h}$ ) using an IVAC (TIVA ALARIS Medical Systems, Hampshire, UK) infusion pump.

\section{Data collection}

Continuous telemetric ECG, pulse, oxygen saturation and respiratory rate monitoring and intermittent (every $10 \mathrm{~min}$ ) blood pressure measurements were performed during and two hours following the experiments (Philips C3 Patient Monitor 862474, USA). During every session, assessments of the blink reflex (see Statistical analysis) took place at the base line and two minutes after each dose increment, respectively.

\section{Psychometric tests}

Immediately after each block of blink reflex recordings certain psychometric parameters were objectively assessed by measuring the speed of reaction and the accuracy of responses to visual stimuli (as described below) and subjectively, using a computer adapted (Matlab 5.3, The MathWorks, Nattick, MA, US) version of Bond Lader Rating Scale [31]. The test consisted of 16 pairs of opposite adjectives, each pair presented separately, with the opposite words delineating a $155 \mathrm{~mm}$ long and $20 \mathrm{~mm}$ wide bar, horizontally centred on a 15 in. Dell computer screen, positioned at a comfortable distance and in an appropriate visual angle. The subjects were instructed to mark the extent to which they felt the two opposite adjectives corresponded to their state of mind (i.e. closer to one quality and more distanced from its opposite) using a cross-hair cursor controlled by a mouse. The distance in $\mathrm{mm}$ was measured, the scores reversed and then analyses were made on three different fields, measuring alertness, calmness and contentedness.

To monitor objectively the subjects' level of alertness a special function was edited in Matlab using Cogent 2000 (version 1.24) to present fifty pairs of either identical or almost identical (four identical digits, one different) five digit figures (Arial size 100), on the same computer screen described above. Each figure was presented for $200 \mathrm{~ms}$ with an inter-figure interval of $400 \mathrm{~ms}$. The subjects were instructed to hit a key (arbitrarily chosen on a keyboard) when the paired figures were identical and a different key when the paired figures were not identical, as soon as possible, after the second figure in each pair was presented. The same keys being used for identical respective different events through the entire test. The reaction time was monitored up to $1000 \mathrm{~ms}$ after the presentation of the second figure in each pair. Slower responses were computerized as errors and excluded from the averaged reaction time in a final (after each test) score of error rate and mean reaction time. The subjects were allowed to familiarize with both tests (reaction performance and Bond Lader Rating Scale) before the first experiment.

\section{Data analysis}

The first recording sweep on all recordings was discarded to avoid contamination by initial startle responses. The onset latency (ms) and the area under the curve AUC $(\mu \mathrm{V}$ $\mathrm{x} \mathrm{ms}$ ) of the R2 component (rectified EMG) between 35 and $95 \mathrm{~ms}$ were calculated by PC-based offline analysis with custom written software programmed in Matlab. Data were recorded on an Excel spreadsheet and checked before the database was locked and the randomisation code was broken. Summary data are presented as mean \pm SEM. Reproducibility between visits was tested with Cronbach's alpha. Data were analysed initially using an ANOVA with repeated measures for an effect of TIME and DRUG treating each study episode as independent. To examine the three independent hypotheses regarding opioid, benzodiazepine and glutamatergic involvement in the nociception-specific blink reflex the ANOVA with repeated measures regarded treatment episodes as related within subjects and examined the DRUG main effect with Bonferroni correction (SPSS for Windows). If Mauchly's test of sphericity was violated, we made appropriate corrections to degrees of freedom according to GreenhouseGeisser. Significance was assessed at the $P<0.05$ level.

\section{Results}

All subjects completed the entire cross-over with no drop-outs. The volunteers had a mass of $72 \pm 8 \mathrm{~kg}$ and were $1.8 \pm 0.1 \mathrm{~m}$ in height. 


\section{Baseline data}

Baseline blood pressure (mean arterial pressure, MAP = $2 / 3$ * Diastolic $+1 / 3$ *Systolic) was $87 \pm 2 \mathrm{mmHg}$, heart rate $62 \pm 2$ beats/min, respiratory rate was $20 \pm 1$ breaths per minute and oxygen saturation $98 \pm 1 \%$.

\section{Blink reflex}

The baseline ipsilateral AUCs ( $\mu$ V.ms) for the four visits (ketamine, diazepam, fentanyl and placebo) were (mean \pm SEM): $2082 \pm 283,1892 \pm 299,2340 \pm 376$ and $2011 \pm 341$, respectively. These were highly reproducible (alpha $=0.85$, Fig. 1a). The baseline ipsilateral latencies (ms) for the four visits were: $41.8 \pm 1.5,43.5 \pm 2.3,42.9 \pm 1.9$ and $45.1 \pm 2.3$, respectively. Again these were highly reproducible (alpha $=0.86$, Fig. 1b). The baseline contralateral AUCs ( $\mu$ V.ms) for the four visits were: $1364 \pm 239,1156 \pm 188,1461 \pm$ 324 and $1336 \pm 306$, respectively. The baseline contralateral latencies (ms) for the four visits were $47 \pm 2,47 \pm 3$, $46 \pm 3$ and $46 \pm 3$, respectively.

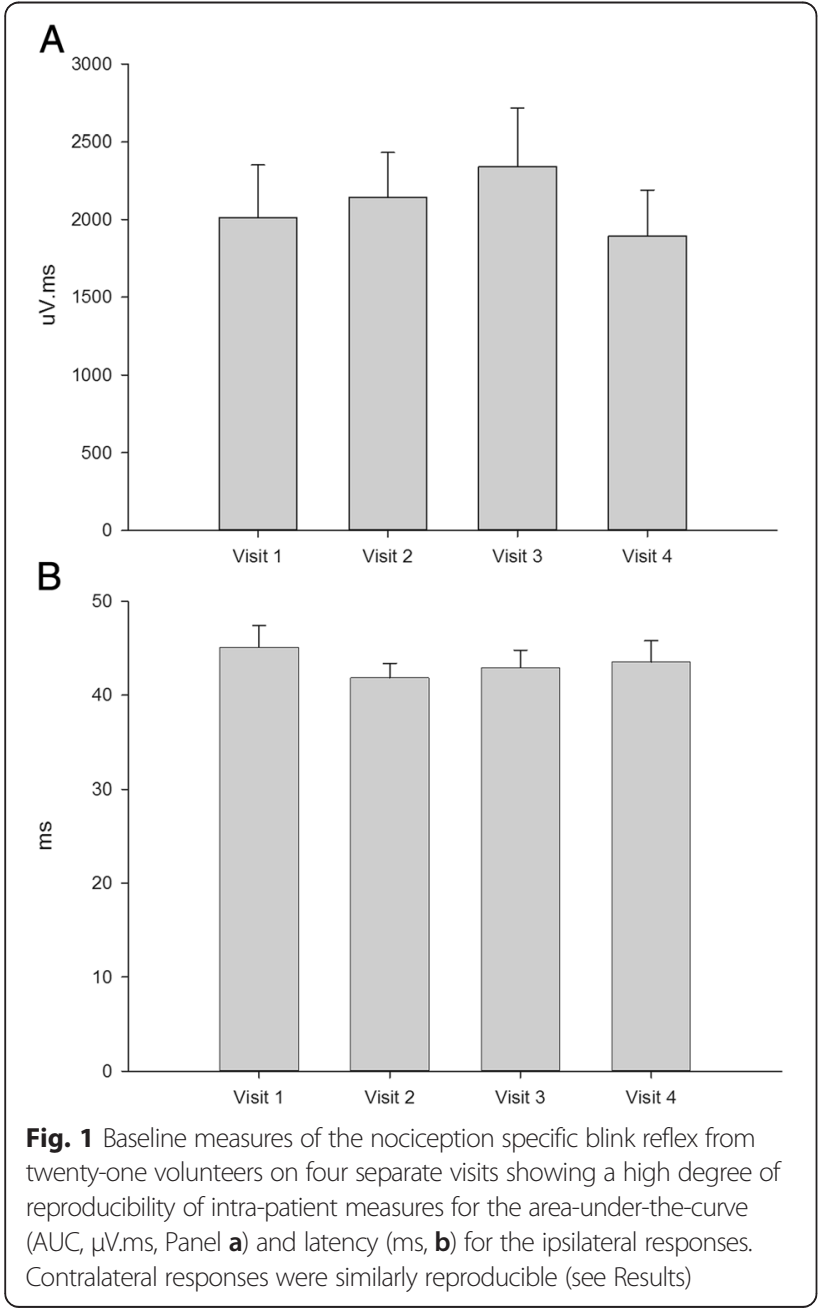

\section{Neuropsychological tests}

From the Bond-Lader scale the alertness (ketamine $30 \pm 4$, diazepam 23 \pm 3 , fentanyl $25 \pm 3$ and placebo $25 \pm 4$ ), calmness $(28 \pm 4,24 \pm 4,27 \pm 4$ and $23 \pm 3)$ and contentedness $(25 \pm 3,21 \pm 3,21 \pm 3$ and $22 \pm 3)$ scores were calculated. Reactions times (ms) for the four visits were: $479 \pm 15,447 \pm 14,406 \pm 17$ and $379 \pm 18$, respectively. Error rates for the four visits were: $13 \pm 2,15 \pm 2,17 \pm 2$ and $16 \pm 2$, respectively.

\section{Overall analysis}

\section{Electrophysiology}

The ipsilateral AUC demonstrated a reduction with time during the four measurement points in the overall analysis $\left(F_{2.0,162.4}=15.6, P<0.001\right)$. There was a significant reduction in ipsilateral AUC attributable to the variable DRUG $\left(F_{3,80}=3.1, P=0.03\right)$. For the contralateral AUC there was a reduction with time $\left(F_{2.3,175.1}=\right.$ 9.7, $P<0.001)$ without a significant DRUG effect for the overall analysis $(F 3,80=2.6, P=0.057)$. There was no significant effect on the ipsilateral $\left(F_{3,62}=2.4, P=0.064\right)$ or contralateral $\left(F_{3,47}=1.1, P=0.36\right)$ latency attributable to DRUG. Latency data were not further analysed.

\section{Neuropsychology}

From the Bond-Lader scale for the alertness score $\left(F_{3,80}=\right.$ $1.02, P=0.39)$, the calmness score $\left(F_{3,80}=0.79, P=0.51\right)$, or the contentedness score $(F 3,80=0.36, P=0.78)$, there was no effect of DRUG, although there was a subjective reduction in alertness over the measurement points $\left(F_{1.8,141.3}=48.1, P<0.001\right)$ not seen with the calmness or contentedness scores. The reaction time was not affected across the measurement points $\left(F_{3,240}=0.19, P=0.90\right)$ or by DRUG $\left(F_{3,80}=2.1, P=0.10\right)$. The error rates were constant across time $\left(F_{3,237}=1.3 P=0.28\right)$ and not altered by DRUG $\left(F_{3,79}=0.59, P=0.62\right)$.

\section{Treatment effects}

There was a treatment effect across the study due to DRUG $\left(F_{3,60}=7.3, P<0.001\right)$ in the ipsilateral AUC, that was further explored. Similarly there was a significant overall effect of DRUG on contralateral AUC $\left(F_{3,60}=6.02, P<0.001\right)$.

\section{Placebo}

The ipsilateral AUC was constant for the placebo infusion at $2011 \pm 341,1907 \pm 290,2056 \pm 333$ and $1731 \pm$ 258 ( $\mu$ V.ms), respectively, with alpha $=0.96$. Similarly the contralateral AUC was constant at $1336 \pm 306,1305$ $\pm 288,1363 \pm 309$ and $1187 \pm 307$, respectively, and again with alpha $=0.96$. 


\section{Ketamine}

The AUCs were $2144 \pm 288,2445 \pm 335,2480 \pm 328$ and $1955 \pm 256$ ( $\mu$ V.ms), respectively. Ketamine had no effect on the ipsilateral AUC when compared with placebo $(P=0.84)$. Contralateral AUCs were $1377 \pm$ $245,1662 \pm 304,1630 \pm 289$ and $1410 \pm 263$, respectively. There was no significant effect of ketamine on contralateral AUC $(P=1.0)$.

\section{Fentanyl}

For fentanyl ipsilateral AUCs were $2340 \pm 376,2219 \pm$ 294, $1852 \pm 357$ and $1673 \pm 334$ ( $\mu$ V.ms), respectively. There was no effect of fentanyl on ipsilateral AUC compared to placebo $(P=1.0)$. Contralateral AUCs were $1461 \pm 324, \quad 1515 \pm 359, \quad 1158 \pm 295$ and $849 \pm 218$, respectively. There was no significant effect of fentanyl on contralateral AUC $(P=1.0)$.

\section{Diazepam}

For diazepam ipsilateral AUCs were $1892 \pm 299,1301 \pm$ 284, $756 \pm 185$ and $580 \pm 120$ ( $\mu$ V.ms), respectively. There was a significant decrement in ipsilateral AUC with diazepam compared to placebo $(P=0.047$, Fig. 2$)$. Contralateral AUCs were $1156 \pm 188,647 \pm 161,328 \pm 83$ and $284 \pm 78$. The effect of diazepam did not reach statistical significance for the contralateral AUC $(P=0.07)$.

\section{Discussion}

The study demonstrates an effect of benzodiazepine receptor modulation on the nociception-specific blink reflex without a detectable $\mu$-opioid receptor or ketamine (glutamate-NMDA receptor) component in this model. The baseline effects were highly reproducible from session to session within subjects for four visits, consistent and extending previous observations [23], demonstrating the robustness of the method and thus its potential for serial assessments after suitable intervention.

A study by Kaube and colleagues using the novel concentric surface electrode [9] demonstrated an increase of the R2 component greater than $500 \%$ on the headache side during acute migraine attacks [32]. An interictal deficiency in habituation of the nBR in migraine patients and also in asymptomatic individuals with a family history of migraine [33] emphasizes the potential for this reflex in understanding migraine pathophysiology.

\section{Nociception specific blink (nBR) reflex}

The nBRr [9] R2 component is increased by more than $500 \%$ in acute migraine [32]. This response seemed specific to migraine and was not observed in patients with acute frontal sinusitis [34], or in hypnic headache [35]. Interestingly, the nBR does not behave differently from controls in cluster headache in terms of habituation [36], although there is certainly lateralized facilitation [37].

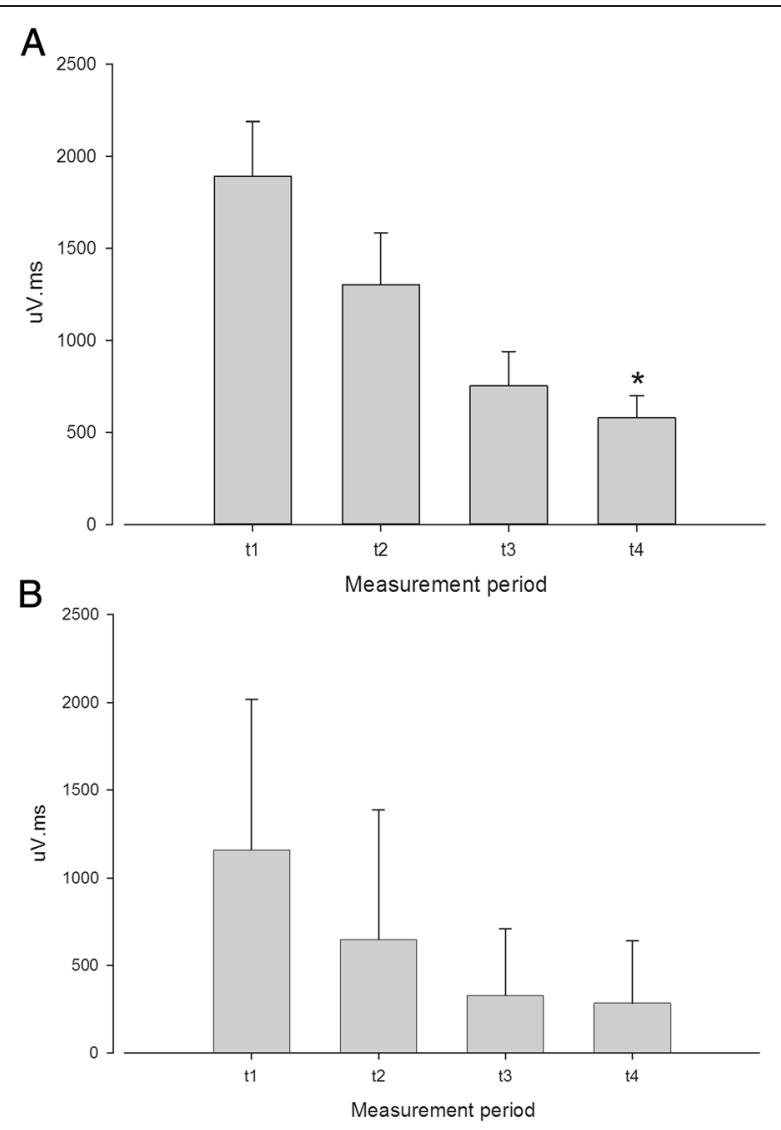

Fig. 2 The effect of the benzodiazepine receptor agonist diazepam on the nociception specific blink reflex, showing a significant $\left({ }^{*}, P<0.05\right)$ reduction in the AUC ( $\mu$ V.ms) ipsilateral to stimulation (Panel a), and no significant effect contralaterally (b). Measurement periods t1 through t4 reflect the data collection epochs

The observation of an interictal persistent change raises the possibility of an endophenotypic marker for migraine [33]. This is important when one considers migraine as a substantially centrally mediated genetic disorder [8]. To this end triptans, serotonin $5-\mathrm{HT}_{1 \mathrm{~B} / 1 \mathrm{D}}$ receptor agonists [38], which are highly effective in migraine [39], have also been reported to affect the nBR. Aspirin and zolmitriptan suppressed the reflex by 68 and $78 \%$, respectively, in migraineurs during an acute attack [40]. Moreover, the $\mathrm{A}_{1}$ receptor agonist GR79236 [41], which is effective in animal models of trigeminovascular nociception [42] and in acute migraine [43], also significantly inhibited the nBR. Taken together the data suggest that the model is helpful in understanding likely effects of various agents in migraine.

\section{nBR human pharmacology}

It has been reported that fentanyl, an opioid receptor agonist, and diazepam, which acts by potentiating the GABA mediated inhibitory effect, both reduce the R2 component of the blink reflex [18]. Dauthier and colleagues [44] found 
that fentanyl $3 \mu \mathrm{g} / \mathrm{kg}$ did not alter the R2 response of the blink reflex. The dose used was slightly higher than the one employed here. Interestingly, fentanyl at a dose of $100 \mu \mathrm{g}$ intramuscularly also failed to affect the R2 component of the blink reflex [45]. Taken with our studies the data suggest that opioid mechanisms are less important in the trigeminal system, although the latter studies were conducted with traditional electrodes with their limitations. In contrast, with the more conventional electrodes, it has been shown that zolmitriptan reverses blink reflex changes seen in migraine [46]. It is interesting that ketamine, despite its use in pain [19] did not alter the nBR. NMDA receptors, as a therapeutic target for migraine therapy have been discussed by Nicolodi and Sicutieri [20] who found that ketamine was effective as acute and preventive migraine treatment, when compared to placebo. Interestingly, when used in migraine with hemiplegic or prolonged aura, ketamine is useful for the aura component but not for the pain $[21,47]$.

\section{Trigeminocervical nociceptive pharmacology}

The new data are broadly consistent with those from lower species with some caveats [38]. Diazepam modulates the $\mathrm{GABA}_{\mathrm{A}}$ receptor, and it has been clearly shown in animals that $\mathrm{GABA}_{\mathrm{A}}$ mechanisms can modulate nociceptive trigeminovascular transmission at the second order synapse in the trigeminocervical complex [48]. Similarly, more direct evidence can be seen with studies of the benzodiazepine receptor in the anaesthetized cat with midazolam inhibiting transmission at a site where the effect is reversed by flumazenil [49]. Interestingly, in humans, the changes induced by diazepam on the R2 component of the blink reflex, were only partially reversed by flumazenil [18]. There is also a body of evidence from studies of neurogenically-mediated dural mechanisms for a role of GABA receptors in this system [50-52]. In contrast to the new data, animal studies do suggest the existence of the mu-opioid receptor in the trigeminocervical complex [53]. Similarly, there is certainly glutamatergic transmission at the trigeminocervical complex [54-56] and again effects in dural models $[57,58]$, suggesting a dose or more crucial difference in terms of human trigeminal nociceptive transmission.

It might be argued that diazepam's influence on the R2 component of the blink reflex is due to a muscle relaxant effect. However, this was not observed in the current study with fentanyl. Moreover, previous work demonstrated a significant reduction of the $\mathrm{R} 2$ response with diazepam doses that did not alter the R1 response $[44,59]$. Since R1 and R2 are mediated by the same muscle groups, a muscle relaxant effect as an explanation for the R2 response reduction seen after diazepam administration is not likely.

\section{Limitations}

The study has some important limitations that need consideration. When studying human volunteers it is imperative to consider safety. Such considerations limit the use of sedative treatments, particularly opioids whose major significant short term side effect is respiratory depression. Ketamine may have been under-dosed, although the results are consistent with other published data [47]. Krystal and colleagues [30] found that doses as low as $0.1 \mathrm{mg} / \mathrm{kg}$ caused psychiatric side effects in healthy volunteers when assessed by the Brief Psychiatric Rating Scale. Therefore, we chose a slightly lower dose $(0.084 \mathrm{mg} / \mathrm{kg})$, aiming, for both ethical and scientific purposes, to determine doses with minimal side effects, which is important since there are a paucity of human dose ranging studies of ketamine in this use. Ketamine is a short acting drug [29] with an effect we would expect to last no more than minutes and a small therapeutic window [26]. These pharmacokinetics favor a cumulative dose regimen as employed here [26], with test batteries performed immediately after or within $10 \mathrm{~min}$ after each dose increase. Our findings are also consistent with data showing that ketamine at a slightly lower dose than the total used here was effective as reducing the anxiety without altering the pain scores [28]. It is important to note the outcome of the study is limited to the pharmacology of the response elicited by the $\mathrm{nBR}$, and cannot be generalized to the entire trigeminal system. Moreover, by using the nBR rather than a pain scale, we are limited in drawing inferences about how subjects may rate pain effects with these drugs.

\section{Conclusions}

We have shown in a carefully conducted three-way crossover study in volunteers a reduction of the nociception specific blink reflex with the benzodiazepine receptor agonist diazepam. We have seen no clear effect of fentanyl, the mu-opioid receptor agonist or ketamine, the non-competitive glutamate NMDAreceptor blocker. The study showed a highly reproducible baseline from week to week within subjects. The nociception specific blink reflex offers a reproducible, quantifiable window with which to examine the trigeminal nociceptive system in humans. Studies of preventive medicines and putative new anti-migraine treatments may provide useful insights into both the pathophysiology of migraine and help accelerate medicine development.

\section{Authors' contributions}

JCAM saw all the patients and conducted all the infusion studies, collected the data and revised the manuscript. AG designed the data collection system and revised the manuscript. KP designed the data collection system and revised the manuscript. HK designed the stimulation and data collection system, and revised the manuscript. PJG contributed clinical data, analytic review and wrote the manuscript. All authors read and approved the final manuscript. 


\section{Acknowledgements}

The authors thank Paul Hammond for excellent technical assistance and Anna Stefanovic for assistance with some of these studies. Some parts of the King's CRF are funded by the South London and the Maudsley Mental Health BRC. The views expressed are those of the authors and not necessarily those of the UK NHS, the NIHR or the Department of Health.

\section{Competing interests}

JCAM (h.marin@nhs.net): has received honoraria and consulting fees from electroCore LLC.

AG (a.gantenbein@rehaclinic.ch): reports no conflicts of interest with the current work.

KP (Koen.Paemeleire@uzgent.be): received honoraria as a speaker, advisor or investigator in clinical studies from Allergan, Almirall, Autonomic

Technologies Inc, Coherex, Janssen-Cilag, Medtronic, Pfizer, Sandoz, and St Jude Medical.

HK (holger.kaube@gmail.com): HK has consulted for Autonomic Technologies Inc and received honoraria for lectures from Allergan.

PJG is on the Advisory Board of eNeura, and has had grant support for experimental research. He is on Advisory Boards for Allergan, Colucid, MAP pharmaceuticals, Merck, Sharpe and Dohme, Autonomic Technologies Inc, Boston Scientific, Electrocore, Eli-Lilly, Medtronic, Linde gases, Arteaus, AlderBio and BristolMyerSquibb. He has consulted for Pfizer, Nevrocorp, Lundbeck, Zogenix, Impax, Zosano and DrReddy, and has been compensated for expert legal testimony. He has grant support from Allergan, Amgen, MAP, and MSD. He has received honoraria for editorial work from Journal Watch Neurology and for developing educational materials and teaching for the American Headache Society.

\section{Author details}

${ }^{1}$ NIHR-Wellcome Trust King's Clinical Research Facility, King's College Hospital, London, UK. 'Department of Basic and Clinical Neuroscience, Institute of Psychiatry, Psychology and Neuroscience, King's College, London, UK. ${ }^{3}$ Wellcome Foundation Building, King's College Hospital, London SE5 9PJ, UK. ${ }^{4}$ Current address: Neurorehabilitation Center, RehaClinic, Bad Zurzach, Switzerland. ${ }^{5}$ Current address: University of Zurich, Zürich, Switzerland. ${ }^{6}$ Current address: Department of Neurology, Ghent University Hospital, Ghent, Belgium. ${ }^{7}$ Neurology and Headache Center, Munich, Germany.

\section{Received: 13 July 2015 Accepted: 2 September 2015}

\section{Published online: 08 October 2015}

\section{References}

1. Lipton RB, Stewart WF, Diamond S, Diamond ML, Reed M (2001) Prevalence and burden of migraine in the United States: data from the American Migraine Study II. Headache 41:646-657

2. Vos T, Flaxman AD, Naghavi M, Lozano R, Michaud C, Ezzati M, Shibuya K, Salomon JA, Abdalla S, Aboyans V, Abraham J, Ackerman I, Aggarwal R, Ahn SY, Ali MK, Alvarado M, Anderson HR, Anderson LM, Andrews KG, Atkinson C, Baddour LM, Bahalim AN, Barker-Collo S, Barrero LH, Bartels DH, Basanez MG, Baxter A, Bell ML, Benjamin EJ, Bennett D, et al (2012) Years lived with disability (YLDs) for 1160 sequelae of 289 diseases and injuries 1990-2010: a systematic analysis for the Global Burden of Disease Study 2010. Lancet 380(9859):2163-2196, PubMed

3. Andlin-Sobocki P, Jonsson B, Wittchen HU, Olesen J (2005) Cost of disorders of the brain in Europe. Eur J Neurol 12(Suppl 1):1-27

4. Goadsby PJ, Lipton RB, Ferrari MD (2002) Migraine- current understanding and treatment. N Engl J Med 346:257-270

5. Goadsby PJ (2013) Therapeutic prospects for migraine: can paradise be regained? Ann Neurol 74:423-434

6. Dodick DW, Goadsby PJ, Silberstein SD, Lipton RB, Olesen J, Ashina M, Wilks K, Kudrow D, Kroll R, Kohrman B, Bargar R, Hirman J, Smith J (2014) Randomized, double-blind, placebo-controlled, phase II trial of ALD403, an anti-CGRP peptide antibody in the prevention of frequent episodic migraine. Lancet Neurol 13:1100-1107

7. Dodick DW, Goadsby PJ, Spierings ELH, Scherer JC, Sweeney SP, Grayzel DS (2014) CGRP monoclonal antibody LY2951742 for the prevention of migraine: a phase 2, randomized, double-blind, placebo-controlled study. Lancet Neurol 13:885-892

8. Akerman S, Holland P, Goadsby PJ (2011) Diencephalic and brainstem mechanisms in migraine. Nat Rev Neurosci 12:570-584
9. Kaube H, Katsarava Z, Kaufer T, Diener H-C, Ellrich J (2000) A new method to increase the nociception specificity of the human blink reflex. Clin Neurophysiol 111:413-416

10. Magis D, Ambrosini A, Bendtsen L, Ertas M, Kaube H, Schoenen J (2007) Evaluation and proposal for optimalization of neurophysiological tests in migraine: part 1-electrophysiological tests. Cephalalgia 27:1323-1338

11. Kimura J (1989) The blink reflex. In: Kimura J (ed) Electrodiagnosis in diseases of nerve and muscle: principles and practice, 2nd edn. Philadelphia, Davis, pp 307-331

12. Esteban A (1999) A neurophysiological approach to brain stem reflexes. Blink reflex. Neurophysiol Clin 29:7-38

13. Misulis KE (1997) Essentials of clinical neurophysiology, 2nd edn. Boston, MA, Butterworth-Heineman

14. Trontelj MA, Trontelj JV (1978) Reflex arc of the first component of the human blink reflex: a single motoneuron study. J Neurol Neurosurg Psychiatry 41:538-547

15. Ongerboer de Visser BW (1983) Anatomical and functional organization of reflexes involving the trigeminal system in man: jaw reflex, blink reflex, corneal reflex and exteroceptive suppression. Adv Neurol 39:727-738

16. Ellrich J (2000) Brain stem reflexes: probing human trigeminal nociception. News Physiol Sci 15:94-97

17. Ellrich J, Bromm B, Hopf HC (1997) Pain-evoked blink reflex. Muscle Nerve 20:265-270

18. Cruccu G, Ferracuti S, Leardi MG, Fabbri A, Manfredi M (1991) Nociceptive quality of the orbicularis oculi reflexes as evaluated by distinct opiate- and benzodiazepine-induced changes in man. Brain Res 556:209-217

19. Zsigmond EK, Domino EF (1980) Ketamine: clinical pharmacology, pharmacokinetics and current clinical use. Anaesthesiol Rev 7:13-33

20. Nicolodi M, Sicutieri F (1995) Exploration of NMDA receptors in migraine: therapeutic and theoretic implications. Int J Pharmacol Res 15:181-189

21. Afridi S, Giffin NJ, Kaube H, Goadsby PJ (2013) A randomized controlled trial of intranasal ketamine in migraine with prolonged aura. Neurology 80:642-647

22. Holle D, Heber A, Naegel S, Diener HC, Katsarava Z, Obermann M (2014) Influences of smoking and caffeine consumption on trigeminal pain processing. J Headache Pain 15:39, PubMed PMCID: PMC4068369

23. Giffin NJ, Katsarava Z, Pfundstein A, Ellrich J, Kaube H (2004) The effect of multiple stimuli on the modulation of the 'nociceptive' blink reflex. Pain 108:124-128

24. Katsarava Z, Ellrich J, Diener H-C, Kaube H (2002) Optimized stimulation and recording parameters of human 'nociception specific' blink reflex recordings. Clin Neurophysiol 113:1932-1936

25. Hommer DW, Matsuo V, Wolkowitz O, Chrousos G, Greenblatt DJ, Waingartner H, Paul SM (1986) Benzodiazepine sensitivity in normal human subjects. Arch Gen Psychiatry 43:542-551

26. Tucker AP, Kim YI, Nadeson R, Goodchild CS (2005) Investigation of the potentiation effects on fentanyl by ketamine in humans: a double-blinded, randomised, placebo controlled, crossover study of experimental pain. BMC Anesthesiol 5:2

27. Peng P, Sandler A (1999) A review of the use of fentanyl analgesia in the management of acute pain in adults. Anesthesiology 20:576-599

28. Oda A, lida H, Dohi S (2000) Patient anxiety scores after low-dose ketamine or fentanyl for epidural catheter placement. Can J Anaesth 47:910-913

29. Clements JA, Nimmo WS, Grant IS (1982) Bioavailability, pharmacokinetics, and analgesic activity of ketamine in humans. J Pharm Sci 71:539-542

30. Krystal JH, Karper LP, Seibyl JP, Freeman GK, Delaney R, Douglas Bremner J, Heninger GR, Bowers MB, Charney DS (1994) Subanesthetic effects of the noncompetitive NMDA Antagonist, Ketamine, in humans.

Psychotomimentic, perceptual, cognitive and neuroendocrine responses. Arch Gen Psychiatry 51:199-214

31. Bond A, Lader M (1974) The use of analogue scales in rating subjective feelings. Br J Med Psychol 47:211-218

32. Kaube H, Katsarava Z, Przywara S, Drepper J, Ellrich J, Diener H-C (2002) Acute migraine headache. Possible sensitization of neurons in the spinal trigeminal nucleus? Neurology 58:1234-1238

33. Di Clemente L, Coppola G, Magis D, Fumal A, De Pasqua V, Di Piero V, Schoenen J (2007) Interictal habituation deficit of the nociceptive blink reflex: an endophenotypic marker for presymptomatic migraine? Brain $130: 765-770$ 
34. Katsarava Z, Lehnerdt G, Duda B, Ellrich J, Diener H-C, Kaube H (2002) Sensitization of trigeminal nociception specific for migraine but not pain of sinusitis. Neurology 59:1450-1453

35. Holle D, Gaul C, Krebs S, Naegel S, Diener HC, Kaube H, Katsarava Z, Obermann M (2011) Nociceptive blink reflex and pain-related evoked potentials in hypnic headache. Cephalalgia 31(11):1181-1188. doi:10.1177/0333102411412629

36. Holle D, Zillessen S, Gaul C, Naegel S, Kaube H, Diener HC, Katsarava Z Obermann M (2012) Habituation of the nociceptive blink reflex in episodic and chronic cluster headache. Cephalalgia 32:998-1004

37. Holle D, Gaul C, Zillessen S, Naegel S, Krebs S, Diener HC, Katsarava Z, Obermann M (2012) Lateralized central facilitation of trigeminal nociception in cluster headache. Neurology 78:985-992

38. Goadsby PJ (2000) The pharmacology of headache. Prog Neurobiol 62:509-525

39. Ferrari MD, Roon Kl, Lipton RB, Goadsby PJ (2002) Triptan medications to treat acute migraine. Lancet 359:1151-1153

40. Katsarava Z, Limmroth V, Baykal O, Akguen D, Diener HC, Kaube H (2004) Differences of anti-nociceptive mechanisms of migraine drugs on the trigeminal pain processing during and outside acute migraine attacks. Cephalalgia 24:657-662

41. Giffin NJ, Kowacs F, Libri V, Williams P, Goadsby PJ, Kaube H (2003) Effect of adenosine $A_{1}$ receptor agonist GR79236 on trigeminal nociception with blink reflex recordings in healthy human subjects. Cephalalgia 23:287-292

42. Goadsby PJ, Hoskin KL, Storer RJ, Edvinsson L, Connor HE (2002) Adenosine (A1) receptor agonists inhibit trigeminovascular nociceptive transmission. Brain 125:1392-1401

43. Humphrey PP, Bland-Ward PA, Carruthers AM, Connor HE, Feniuk W, Honey AC, Thomas M (2001) Inhibition of trigeminal nociceptive afferents by adenosine $A_{1}$ receptor activation: a novel approach towards the design of new anti-migraine compounds. Cephalalgia 21:268-269

44. Dauthier C, Gaudy JH, Bonnet B (1981) Comparative study of the effects of diazepam and fentanyl on the blink reflex threshold in the normal, conscious human. Ann Anesthesiol Fr 22:317-321

45. Romaniello A, Valls-Sole J, lannetti GD, Truini A, Manfredi M, Cruccu G (2002 Nociceptive quality of the laser-evoked blink reflex in humans. J Neurophysiol 87:1386-1394

46. de Tommaso M, Guido M, Libro G, Sciruicchio V, Puca F (2000) Zolmitriptan reverses blink reflex changes induced during the migraine attack in humans. Neurosci Lett 289:57-60

47. Kaube H, Herzog J, Kaufer T, Dichgans M, Diener HC (2000) Aura in some patients with familial hemiplegic migraine can be stopped by intranasal ketamine. Neurology 55:139-141

48. Storer RJ, Akerman S, Goadsby PJ (2001) GABA receptors modulate trigeminovascular nociceptive neurotransmission in the trigeminocervical complex. Br J Pharmacol 134:896-904

49. Storer RJ, Akerman S, Shields KG, Goadsby PJ (2004) GABAA receptor modulation of trigeminovascular nociceptive neurotransmission by midazolam is antagonized by flumazenil. Brain Res 1013:188-193

50. Lee WK, Limmroth V, Ayata C, Cutrer FM, Waeber C, Yu X-Y, Moskowitz MA (1995) Peripheral GABA-A receptor mediated effects of sodium valproate on dural plasma protein extravasation to substance $P$ and trigeminal stimulation. Br J Pharmacol 116:1661-1667

51. Limmroth V, Lee WS, Cutrer FM, Moskowitz MA (1996) GABA_-receptormediated effects of progesterone, its ring-A-reduced metabolites and synthetic neuroactive steroids on neurogenic oedema in the rat meninges. Br J Pharmacol 117:99-104

52. Cutrer FM, Moskowitz MA (1996) The actions of valproate and neurosteroids in a model of trigeminal pain. Headache 36(10):579-585

53. Storer RJ, Akerman S, Goadsby PJ (2003) Characterization of opioid receptors that modulate nociceptive neurotransmission in the trigeminocervical complex. Br J Pharmacol 138:317-324

54. Storer RJ, Goadsby PJ (1999) Trigeminovascular nociceptive transmission involves $\mathrm{N}$-methyl-D-aspartate and non-N-methyl-D-aspartate glutamate receptors. Neuroscience 90:1371-1376

55. Classey JD, Knight YE, Goadsby PJ (2001) The NMDA receptor antagonist MK-801 reduces Fos-like immunoreactivity within the trigeminocervical complex following superior sagittal sinus stimulation in the cat. Brain Res 907:117-124

56. Goadsby PJ, Classey JD (2000) Glutamatergic transmission in the trigeminal nucleus assessed with local blood flow. Brain Res 875:119-124
57. Mitsikostas DD, Sanchez del Rio M, Waeber C, Moskowitz MA, Cutrer FM (1998) The NMDA receptor antagonist MK-801 reduces capsaicin-induced c-fos expression within rat trigeminal nucleus caudalis. Pain 76:239-248

58. Mitsikostas DD, Sanchez del Rio M, Waeber C, Huang Z, Cutrer FM, Moskowitz MA (1999) Non-NMDA glutamate receptors modulate capsaicin induced c-fos expression within trigeminal nucleus caudalis. Br J Pharmacol 127:623-630

59. Kimura J (1973) The blink reflex as a test for brain stem and higher centra nervous function. In: Desmet JE (ed) New developments in electromyography and clinical neurophysiology 3. Karger, Basel, pp 682-691

\section{Submit your manuscript to a SpringerOpen ${ }^{\odot}$ journal and benefit from:}

- Convenient online submission

- Rigorous peer review

- Immediate publication on acceptance

- Open access: articles freely available online

- High visibility within the field

- Retaining the copyright to your article

Submit your next manuscript at $>$ springeropen.com 